Pacific Journal of Mathematics

SUBALGEBRAS OF FINITE CODIMENSION IN THE ALGEBRA
OF ANALYTIC FUNCTIONS ON A RIEMANN SURFACE 


\section{SUBALGEBRAS OF FINITE CODIMENSION IN THE ALGEBRA OF ANALYTIC FUNCTIONS ON A RIEMANN SURFACE}

\section{BRUCE Lund}

Let $R$ be a finite open Riemann surface with boundary $\Gamma$. We set $\bar{R}=R \cup \Gamma$ and let $A(R)$ denote the algebra of functions which are continuous on $\bar{R}$ and analytic on $R$. Suppose $A$ is a uniform algebra contained in $A(R)$. The main result of this paper shows that if $A$ contains a function $F$ which is analytic in a neighborhood of $\bar{R}$ and which maps $\bar{R}$ in a $n$-toone manner (counting multiplicity) onto $\{z:|z| \leqq 1\}$, then $A$ has finite codimension in $A(R)$.

We say that $A$ is a uniform algebra on $\bar{R}$ if $A$ is a uniformly closed subalgebra of the complex-valued continuous functions on $\bar{R}$ which separates points of $\bar{R}$ and contains the constant functions. If $A$ is contained in $A(R)$, then we say $A$ has finite codimension in $A(R)$ if $A(R) / A$ is a finite dimensional vector space over $C$. A reference for uniform algebras is Gamelin [2].

Let $U$ be the open unit disk in $C$. We call $F$ an unimodular function if $F$ is analytic in a neighborhood of $\bar{R}$ and maps $\bar{R}$ onto $\bar{U}$ so that $F$ is $n$-to-one if we count the multiplicity of $F$ where $d F$ vanishes. If $T$ is the unit circle, then $F$ maps $\Gamma$ onto $T$. The existence of such a function was first proved by Ahlfors [1]. Later, Royden [4] gave another proof of this result.

1. Main results. Let $A$ be a uniform algebra on $\bar{R}$ which is contained in $A(R)$. If $J=\{f \in A(R): f A(R) \subset A\}$, then $J$ is a closed ideal in $A(R)$ and $J$ is contained in $A$.

Lemma. Let $F \in A$ be an unimodular function of order n. If $\zeta_{1} \in \bar{R}$ is such that $F^{-1}\left(F\left(\zeta_{1}\right)\right)$ consists of $n$ distinct points, then there is $G \in J$ such that $G\left(\zeta_{1}\right) \neq 0$.

Proof. Since $A$ separates points on $\bar{R}$, there is $g \in A$ such that $g$ separates $F^{-1}\left(F\left(\zeta_{1}\right)\right)$. If $z_{1} \in \bar{R}$, let $F^{-}\left(F\left(z_{1}\right)\right)=\left\{z_{1}, z_{2}, \cdots, z_{n}\right\}$ (perhaps with repetitions) and let $f \in A(R)$.

Define $Q(u)=f\left(z_{1}\right)\left\{u-g\left(z_{2}\right)\right\}\left\{u-g\left(z_{3}\right)\right\} \cdots\left\{u-g\left(z_{n}\right)\right\}+f\left(z_{2}\right)\{u-$ $\left.g\left(z_{1}\right)\right\}\left\{u-g\left(z_{3}\right)\right\} \cdots\left\{u-g\left(z_{n}\right)\right\}+\cdots+f\left(z_{n}\right)\left\{u-g\left(z_{1}\right)\right\}\left\{u-g\left(z_{2}\right)\right\} \cdots\{u-$ $\left.g\left(z_{n-1}\right)\right\}$ (cf. [5], p. 290). Then $Q(u)$ is a polynomial in $u$ of the form $Q(u)=\alpha_{n-1}\left(z_{1}, \cdots, z_{n}\right) u^{n-1}+\alpha_{n-2}\left(z_{1}, \cdots, z_{n}\right) u^{n-2}+\cdots+\alpha_{0}\left(z_{1}, \cdots, z_{n}\right)$. The coefficients $\alpha_{j}$ are symmetric functions in $z_{1}, \cdots, z_{n}$. Hence, if 
$w=F\left(z_{1}\right)$, then $a_{j}(w)=\alpha_{j}\left(z_{1}, \cdots, z_{n}\right)$ for $j=0, \cdots, n-1$ is well-defined on $\bar{U}$. Using Riemann's removable singularity theorem, it follows that $a_{j}(w) \in A(U)$ for $j=0, \cdots, n-1$.

Since $a_{j}(w) \in A(U)$ for each $j$, there are polynomials $\left\{p_{k}^{j}(w)\right\}_{k=1}^{\infty}$ such that the $p_{k}^{j}$ 's converge uniformly to $a_{j}$ on $\bar{U}$. Then $p_{k}^{j}(F(z)) \in A$ for each $k$, and we conclude that $a_{j}(F(z)) \in A$. Letting $z=z_{1}$ and setting $u=g(z)$, we obtain $Q(g(z))=a_{n-1}(F(z)) g(z)^{n-1}+a_{n-2}(F(z)) g(z)^{n-2}+\cdots$ $+a_{0}(F(z))=f(z) \prod_{i=2}^{n}\left\{g(z)-g\left(z_{2}\right)\right\} \in A$. Let $G(z)=\prod_{i=2}^{n}\left\{g(z)-g\left(z_{2}\right)\right\}$. Then $G\left(\zeta_{1}\right) \neq 0$ and we have shown that $f G \in A$ for any $f \in A(R)$. Therefore, $G \in J$.

THEOREM. Let $A$ be a uniform algebra on $\bar{R}$ which is contained in $A(R)$. If $A$ contains an unimodular function, then $A$ has finite codimension in $A(R)$.

Proof. Suppose $F \in A$ is an unimodular function of order $n$. Let hull $J=\{z \in \bar{R}: f(z)=0$ for all $f \in J\}$. If $\zeta \in \Gamma$, then $d F(\zeta) \neq 0$ ([7], p. 367) and consequently $F^{-1}(F(\zeta))$ consists of $n$ distinct points. By the lemma, hull $J \subset R$. It follows that hull $J$ is a finite set. By applying [6], Theorem 1 and [3], Lemma 2.5, we conclude that $A(R) / J$ is finite dimensional. Hence, $A$ has finite codimension in $A(R)$.

Let $R=\{z \in C: 1<|z|<2\}$. Again let $J=\{f \in A(R): f A(R) \subset A\}$ where $A$ is a uniform algebra on $\bar{R}$. Using the same technique we prove the proposition below.

Proposition. Let $A$ be a uniform algebra on $\bar{R}$ which is contained in $A(R)$. If $A$ contains $z^{n}$ and $z^{-m}$ for some positive integers $n$ and $m$, then $A=A(R)$.

Proof. Let $N$ be the least common multiple of $n$ and $m$. Then $z^{N}$ and $z^{-N} \in A$. Also, $z^{N}$ is an $N$-to-one map of $\bar{R}$ onto $\bar{R}$ without branch points. For any $\zeta_{1} \in \bar{R}$ there are $N$ distinct points $\left\{\zeta_{1}, \zeta_{2}, \cdots, \zeta_{N}\right\}$ which satisfy $\zeta_{i}^{N}=\zeta_{1}^{N}$. Fix $\zeta_{1} \in \bar{R}$ and let $g \in A$ separate $\left\{\zeta_{1}, \zeta_{2}, \cdots, \zeta_{N}\right\}$. Let $f \in A(R)$.

Letting $z^{N}$ take the role of $F$ and using $g$ and $f$, we form $Q(u)$ just as in the proof of the lemma. The coefficients $a_{j}(w)$ of $Q(u)$ belong to $A(R)$. Hence there are polynomials in $w$ and $w^{-1}$ which converge uniformly to $a_{j}(w)$ on $\bar{R}$. Since $z^{N}$ and $z^{-N}$ belong to $A$, it follows that $a_{j}\left(z^{N}\right)$ is in $A$.

Consequently, $Q(g(z))=f(z) \prod_{i=2}^{N}\left\{g(z)-g\left(z_{2}\right)\right\} \in A$ for all $f \in A(R)$. Let $G(z)=\prod_{i=2}^{N}\left\{g(z)-g\left(z_{i}\right)\right\}$. Then $G \in J$ and $G\left(\zeta_{1}\right) \neq 0$. Therefore, hull $J=\dot{\phi}$. This implies $A=A(R)$.

2. Question. The theorem of this paper gives an affirmative 
answer to a special case of the following question. Suppose $A$ is a uniform algebra on $\bar{R}$ and $A$ is contained in $A(R)$. If $A$ contains a nonconstant function which is analytic in a neighborhood of $\bar{R}$, does it follow that $A$ has finite codimension in $A(R)$ ?

\section{REFERENCES}

1. L. V. Ahlfors, Open Riemann surfaces and extremal problems on compact subregions, Comment. Math. Helv., 24 (1950), 100-134.

2. T. W. Gamelin, Uniform Algebras, Prentice-Hall, Englewood Cliffs, N. J., 1969.

3. A. Read, A converse of Cauchy's theorem and application to extremal problems, Acta Math., 100 (1958), 1-22.

4. H. L. Royden, The boundary values of analytic and harmonic functions, Math. Z., 78 (1962), 1-24.

5. G. Springer, Introduction to Riemann Surfaces, Addison-Wesley, Reading, Mass., 1957.

6. C. M. Stanton, The closed ideals of a function algebra, Trans. Amer. Math. Soc., 154 (1971), 289-300.

7. E. L. Stout, On some algebras of analytic functions on finite open Riemann surfaces, Math. Z., 92 (1966), 366-379.

Received February 22, 1973 and in revised form June 25, 1973.

The University of NeW Brunswick 



\section{PACIFIC JOURNAL OF MATHEMATICS}

\section{EDITORS}

RICHARD ARENS (Managing Editor)

University of California

Los Angeles, California 90024
J. DUGUNDJI*

Department of Mathematics

University of Southern California

Los Angeles, California 90007

D. Gilbarg and J. Milgram

Stanford University

Stanford, California 94305
University of Washington

Seattle, Washington 98105

ASSOCIATE EDITORS
E. F. BECKENBACH
B. H. NeumanN
F. WoLF
K. YosHIDA

\section{SUPPORTING INSTITUTIONS}

\author{
UNIVERSITY OF BRITISH COLUMBIA \\ CALIFORNIA INSTITUTE OF TECHNOLOGY \\ UNIVERSITY OF CALIFORNIA \\ MONTANA STATE UNIVERSITY \\ UNIVERSITY OF NEVADA \\ NEW MEXICO STATE UNIVERSITY \\ OREGON STATE UNIVERSITY \\ UNIVERSITY OF OREGON \\ OSAKA UNIVERSITY
}

\author{
UNIVERSITY OF SOUTHERN CALIFORNIA \\ STANFORD UNIVERSITY \\ UNIVERSITY OF TOKYO \\ UNIVERSITY OF UTAH \\ WASHINGTON STATE UNIVERSITY \\ UNIVERSITY OF WASHINGTON
* * * *
AMERICAN MATHEMATICAL SOCIETY \\ NAVAL WEAPONS CENTER
}

The Supporting Institutions listed above contribute to the cost of publication of this Journal, but they are not owners or publishers and have no responsibility for its content or policies.

Mathematical papers intended for publication in the Pacific Journal of Mathematics should be in typed form or offset-reproduced, (not dittoed), double spaced with large margins. Underline Greek letters in red, German in green, and script in blue. The first paragraph or two must be capable of being used separately as a synopsis of the entire paper. Items of the bibliography should not be cited there unless absolutely necessary, in which case they must be identified by author and Journal, rather than by item number. Manuscripts, in duplicate if possible, may be sent to any one of the four editors. Please classify according to the scheme of Math. Rev. Index to Vol. 39. All other communications to the editors should be addressed to the managing editor, or Elaine Barth, University of California, Los Angeles, California, 90024.

100 reprints are provided free for each article, only if page charges have been substantially paid. Additional copies may be obtained at cost in multiples of 50 .

The Pacific of Journal Mathematics is issued monthly as of January 1966. Regular subscription rate: $\$ 72.00$ a year (6 Vols., 12 issues). Special rate: $\$ 36.00$ a year to individual members of supporting institutions.

Subscriptions, orders for back numbers, and changes of address should be sent to Pacific Journal of Mathematics, 103 Highland Boulevard, Berkeley, California, 94708.

PUBLISHED BY PACIFIC JOURNAL OF MATHEMATICS, A NON-PROFIT CORPORATION

Printed at Kokusai Bunken Insatsusha (International Academic Printing Co., Ltd.), 270, 3-chome Totsuka-cho, Shinjuku-ku, Tokyo 160, Japan.

* C. R. DePrima California Institute of Technology, Pasadena, CA 91109, will replace J. Dugundji until August 1974.

Copyright (C) 1973 by Pacific Journal of Mathematics

Manufactured and first issued in Japan 


\section{Pacific Journal of Mathematics}

\section{Vol. 51, No. $2 \quad$ December, 1974}

Robert F. V. Anderson, Laplace transform methods in multivariate spectral theory .................................................. 339

William George Bade, Two properties of the Sorgenfrey plane . . . . . . . . . . . . 349

John Robert Baxter and Rafael Van Severen Chacon, Functionals on continuous

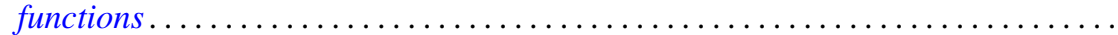

Phillip Wayne Bean, Helly and Radon-type theorems in interval convexity

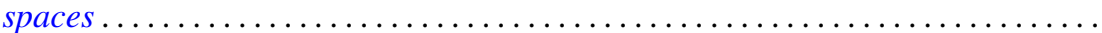

James Robert Boone, On k-quotient mappings $\ldots \ldots \ldots \ldots \ldots \ldots \ldots \ldots \ldots$

Ronald P. Brown, Extended prime spots and quadratic forms . . . . . . . . . . . .

William Hugh Cornish, Crawley's completion of a conditionally upper continuous lattice .............................................

Robert S. Cunningham, On finite left localizations ...................

Robert Jay Daverman, Approximating polyhedra in codimension one spheres

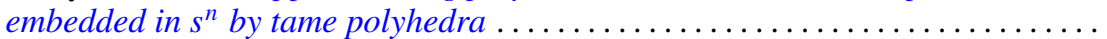

Burton I. Fein, Minimal splitting fields for group representations . . . . . . . . . . . .

Peter Fletcher and Robert Allen McCoy, Conditions under which a connected

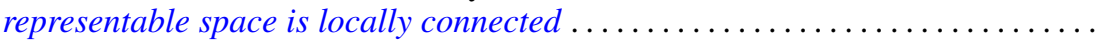

Jonathan Samuel Golan, Topologies on the torsion-theoretic spectrum of a noncommutative ring...

Manfred Gordon and Edward Martin Wilkinson, Determinants of Petrie matrices.

Alfred Peter Hallstrom, A counterexample to a conjecture on an integral condition for determining peak points (counterexample concerning peak points)........

E. R. Heal and Michael Windham, Finitely generated $F$-algebras with applications to Stein manifolds.

Denton Elwood Hewgill, On the eigenvalues of a second order elliptic operator in an unbounded domain ............................

Charles Royal Johnson, The Hadamard product of $A$ and $A^{*}$.

Darrell Conley Kent and Gary Douglas Richardson, Regular completions of Cauchy spaces.

Alan Greenwell Law and Ann L. McKerracher, Sharpened polynomial approximation

Bruce Stephen Lund, Subalgebras of finite codimension in the algebra of analytic functions on a Riemann surface. .

Robert Wilmer Miller, TTF classes and quasi-generators . .

Roberta Mura and Akbar H. Rhemtulla, Solvable groups in which every maximal partial order is isolated ....

Isaac Namioka, Separate continuity and joint continuity...

Alan Saleski, Entropy of self-homeomorphisms of statistical pseudo-metric

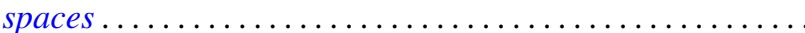

H. A. Seid, Cyclic multiplication operators on $L_{p}$-spaces .....

H. B. Skerry, On matrix maps of entire sequences ............

John Brendan Sullivan, A proof of the finite generation of invariants of a normal

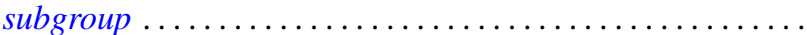

John Griggs Thompson, Nonsolvable finite groups all of whose local subgroups are

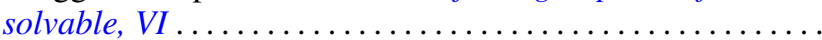

